\title{
Polymorphism in 2-Chlorobenzamide - Run of the Mill or Not?
}

\author{
Jeremy K. Cockcroft ${ }^{\dagger}$,Asma B. M. Buanz $z^{\dagger}$,Anastasia Ntantou ${ }^{\dagger}$, , Louise S. Price ${ }^{\dagger}$, Derek A. \\ Tocher $^{\dagger}$, Martin Vickers ${ }^{\dagger}$ and Robert W. Lancaster ${ }^{\dot{H}^{*}}$ \\ ${ }^{\dagger}$ Department of Chemistry, University College London, 20 Gordon St London WC1H 0AJ, \\ UK, ${ }^{\dagger}$ UCL School of Pharmacy, 29-39 Brunswick Square, London WC1N 1AX, UK.
}

\section{Supplementary Information}

\section{Contents}

1. Scope and results of the polymorph screen for 2-chlorobenzamide, Table SI 1.

2. Expanded IR spectra: Figure SI 1.1. IR spectra of the commercial material supplied by Sigma-Aldrich and material crystallized from acetonitrile, Figure SI 1.2. IR spectra of the commercial material supplied by Aldrich and material crystallized from dichloromethane, Figure SI 1.3. Infrared spectra of 2-chlorobenzamide $-\alpha$ polymorph crystallized from $\mathrm{CHCl}_{3}$, milled 5, 30, 120 minutes compared to commercial material, ex. Sigma Aldrich ( $\beta$-form).

3. DSC data $\alpha$ and $\beta$ forms (heating rate $10 \%$ min in all cases): Figure SI 2.1. DSC thermogram of $\alpha$-form (measured at $10^{\circ} \mathrm{C} / \mathrm{min}$ ); Figure SI 2.2. DSC thermogram of $\beta$ form (measured at $10^{\circ} \mathrm{C} / \mathrm{min}$ ); Figure SI $2.3 \mathrm{DSC}$ of $\alpha$ and $\beta$ forms at $100^{\circ} \mathrm{C} / \mathrm{min}$.

4. The crystal energy landscape of 2-chlorobenzamide according to motif matches with the experimental forms, Figure SI 3.

5. Calculated powder patterns from the experimentally determined single crystal X-ray structures, Figure SI 4.

6. Results of the variable temperature PXRD experiments on $\alpha$ - and $\beta$-forms of 2chlorobenzamide: Figure SI 5.1 showing the $\beta \rightarrow \alpha$ transition on heating; Tables SI 2.1-2 of derived lattice parameters; Figures SI 5.2-4 showing variation in lattice parameters and volume as a function of temperature. 
1. Table SI 1. Scope and results of an early polymorph screen for 2-chlorobenzamide.

\begin{tabular}{|c|c|c|c|c|c|c|c|}
\hline Solvent $\quad$ Technique & SEBV $^{1}$ & $\mathrm{SESV}^{2}$ & $\mathrm{SCBV}^{3}$ & $\mathrm{SCSV}^{4}$ & $\mathrm{VDIH}^{5}$ & VDIDE $^{6}$ & $\mathrm{LDID}^{7}$ \\
\hline Methanol & $\beta$ & $\beta$ & $\beta$ & $\beta$ & $\beta$ & $\beta$ & - \\
\hline Ethanol & $\beta$ & $\beta$ & $\beta$ & $\beta$ & $\beta$ & $\alpha$ & - \\
\hline 1-Propanol & $\beta$ & $\beta$ & - & $\beta$ & $\mathrm{X}$ & - & - \\
\hline 2-Propanol & $\beta$ & $\beta$ & - & - & $X$ & - & - \\
\hline 1-Butanol & $\beta$ & $\beta$ & $\beta$ & - & $X$ & - & - \\
\hline 2-Butanol & $\beta$ & $\beta$ & $X$ & $\beta$ & $\mathrm{X}$ & - & - \\
\hline Acetonitrile & $\beta$ & $\beta$ & - & $\beta$ & $\beta$ & $\beta$ & - \\
\hline Nitromethane & $\beta$ & - & - & $\beta$ & - & - & - \\
\hline Benzonitrile & $\alpha$ & - & - & $\mathrm{X}$ & - & - & - \\
\hline Toluene & $\alpha$ & - & - & - & - & - & $\alpha$ \\
\hline Octane & $X$ & - & - & - & - & - & $\alpha$ \\
\hline Hexane & $\mathrm{X}$ & - & - & - & - & - & $\alpha$ \\
\hline Cyclohexane & $X$ & - & - & - & - & - & $\alpha$ \\
\hline Butyl Ether & $\beta$ & - & - & - & $\beta$ & - & $\alpha$ \\
\hline Diethyl Ether & $X$ & - & - & - & - & - & $\alpha$ or $\beta$ \\
\hline Isopropyl Ether & $\alpha$ & - & - & - & - & - & - \\
\hline t-Butyl Methyl Ether & $\alpha$ & - & - & - & - & $\alpha$ & - \\
\hline Chloroform & - & - & $\alpha$ & $\alpha$ & - & - & - \\
\hline Dichloromethane & $\alpha$ & - & $\alpha$ & - & $\alpha$ & - & - \\
\hline Tetrachloroethene & $\alpha$ & - & - & - & - & - & - \\
\hline 1,2-Dichloroethane & $\alpha$ & - & - & - & - & - & - \\
\hline 2,2,2 Trifluoroethanol & $\beta$ & $\beta$ & - & $\beta$ & - & + & - \\
\hline Formamide & $\mathrm{X}$ & - & - & - & - & - & - \\
\hline Dimethylformamide & $\beta$ & - & - & - & - & - & - \\
\hline Dimethylsulphoxide & $\beta$ & - & - & - & - & - & - \\
\hline Tetrahydrofuran & $\alpha$ & $\alpha$ & $\beta$ & $\beta$ & - & $\alpha$ or $\beta$ & - \\
\hline Methyl Ethyl Ketone & $\beta$ & - & - & - & - & - & - \\
\hline Methyl Benzoate & $\alpha$ & - & - & - & - & - & - \\
\hline Ethyl Acetate & $\alpha$ or $\beta$ & $\beta$ & - & - & - & $\beta$ & - \\
\hline 1,4-Dioxane & $\alpha$ & $\beta$ & $\beta$ & - & - & $\beta$ & - \\
\hline 1-methyl-2-pyrrolidone & $\mathrm{X}$ & - & - & - & - & - & - \\
\hline Acetone & - & $\beta$ & $\beta$ & $\beta$ & $\beta$ & $\beta$ & - \\
\hline
\end{tabular}

${ }^{1}$ slow evaporation in a $25 \mathrm{ml}$ vial $25^{\circ} \mathrm{C}$.

2 slow evaporation in a $5 \mathrm{ml}$ vial $25^{\circ} \mathrm{C}$.

${ }^{3}$ slow evaporation in a $25 \mathrm{ml}$ vial $5^{\circ} \mathrm{C}$.

${ }^{4}$ slow evaporation in a $5 \mathrm{ml}$ vial $5^{\circ} \mathrm{C}$.

${ }^{5}$ vapour diffusion with hexane.

${ }^{6}$ vapour diffusion with diethyl ether.

${ }^{7}$ liquid diffusion in dichloromethane.

- no experiment carried out.

$\mathrm{X}$ crystallization did not occur. 
Ref. Ntantou A. MSc thesis, 2007.

Footnote: Initial crystallization experiments were carried out using material obtained from Sigma Aldrich ( $\beta$-form). Latterly repeat experiments used material from Alfa-Aesar ( $\alpha$-form). Many of the above recrystallization experiments have been repeated recently, often using material from both sources. Those solvents and conditions that are known to produce the $\beta$ polymorph do so consistently. However, some early results reported as an outcome yielding $\beta$ were in reality, the $\alpha$-form and conversion (or partial conversion) had occurred as a result of harvesting the sample or preparing the sample for analysis. Using extreme care when handling and sampling the $\alpha$-form spectra are reliably obtained that are broadly consistent with the $\alpha$-form. Some degree of minimal conversion to the $\beta$-form can never be entirely ruled out. 


\section{Expanded IR spectra.}

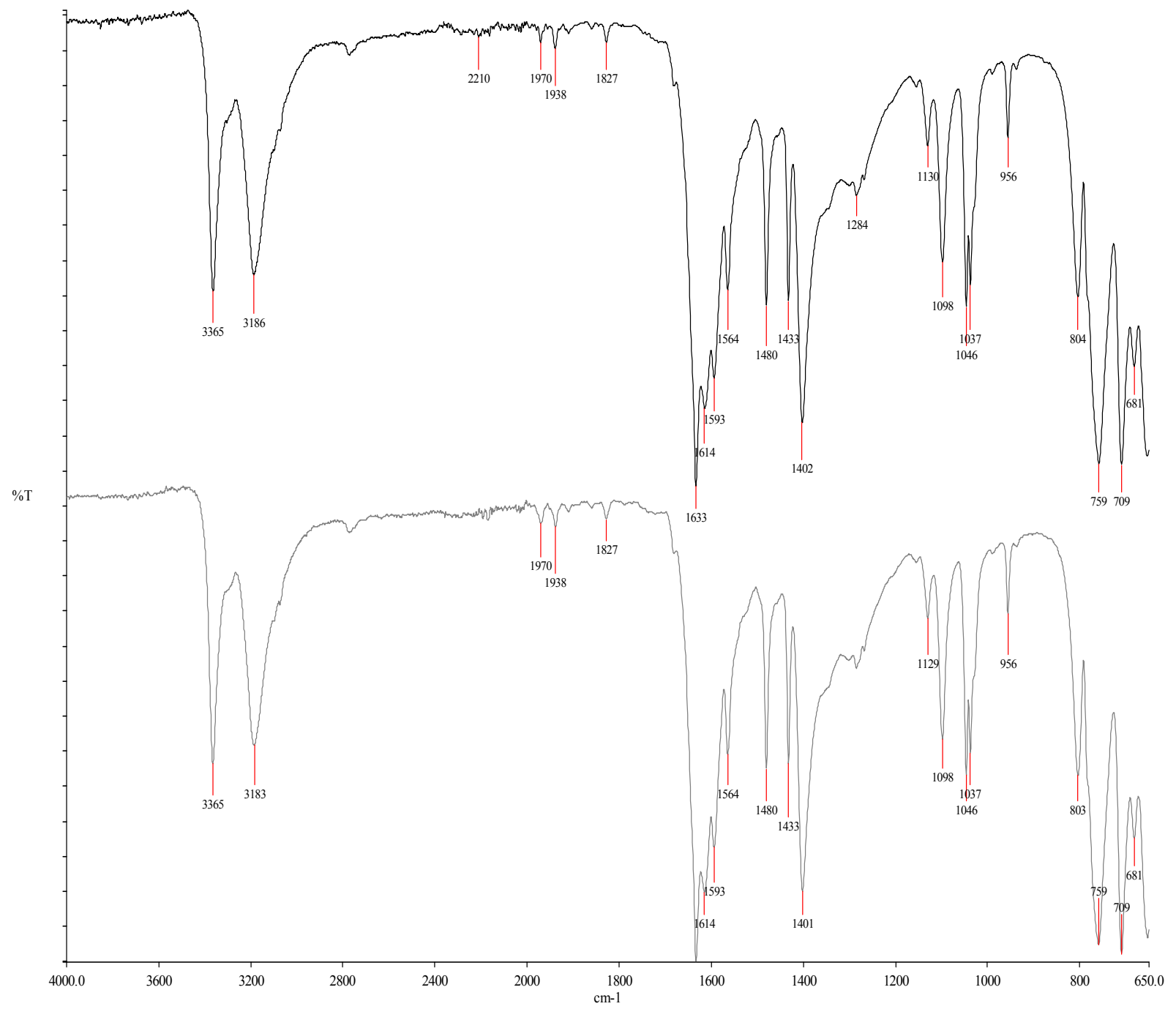

Figure SI 1.1. IR spectra of the commercial material supplied by Sigma-Aldrich (upper) and material crystallized from acetonitrile (lower). 


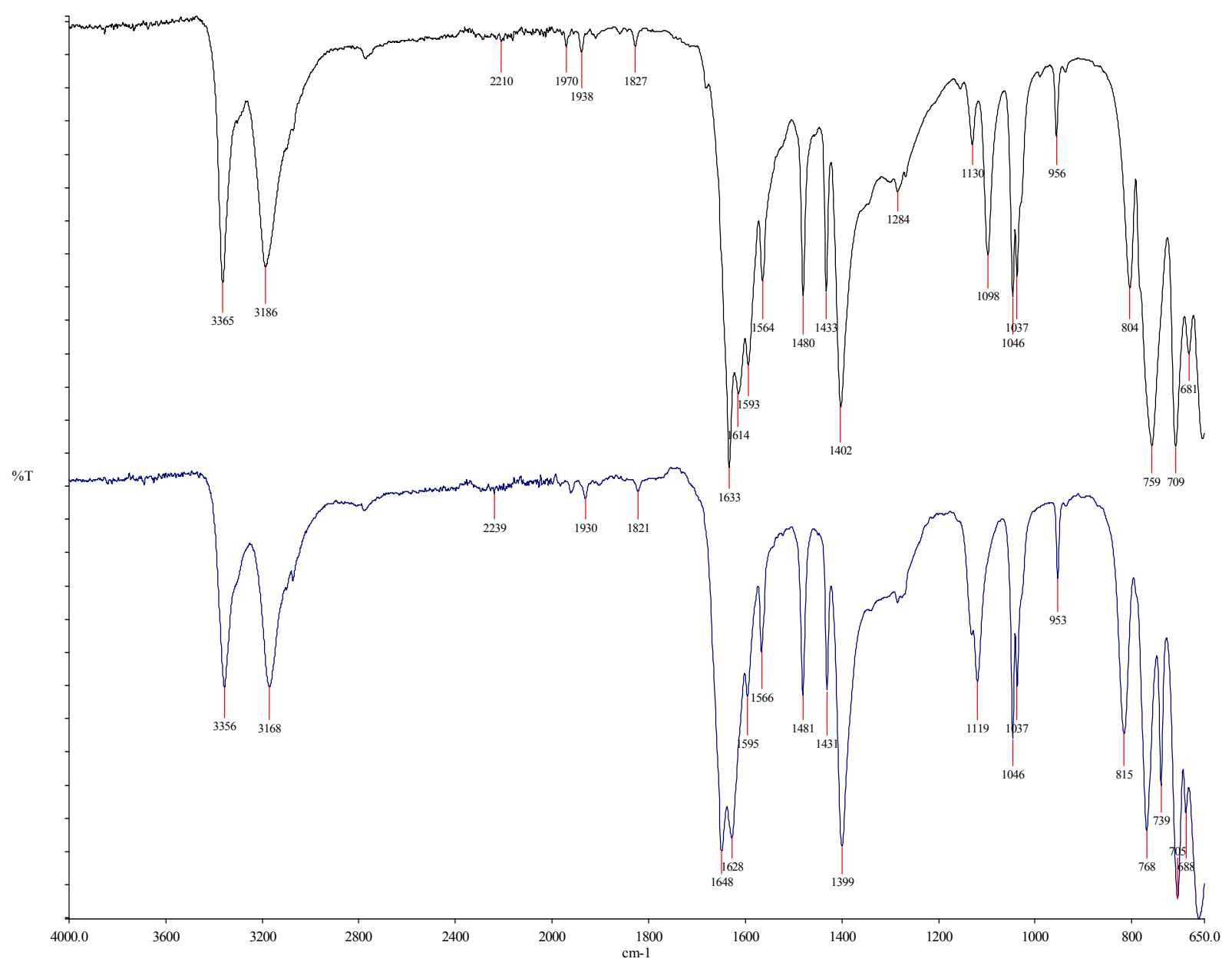

Figure SI 1.2. IR spectra of the commercial material supplied by Sigma-Aldrich (upper) and material crystallized from dichloromethane (lower). 


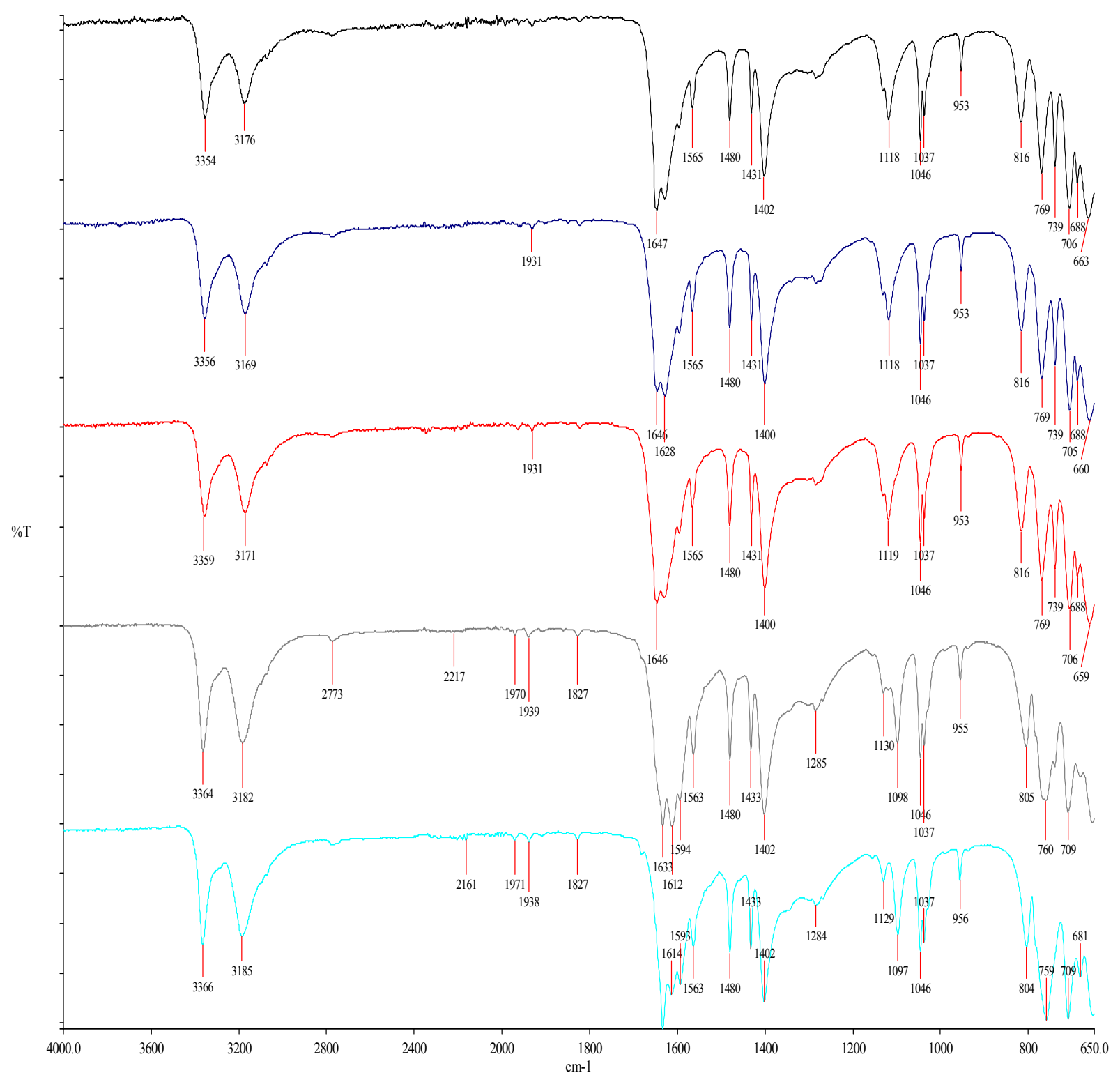

Figure SI 1.3. Infrared spectra of 2-chlorobenzamide $-\alpha$-polymorph crystallized from. $\mathrm{CHCl}_{3}$ (top), milled 5, 30, 120 minutes, commercial material, ex. Sigma Aldrich, $\beta$-form (bottom). 
3. DSC data on the $\alpha$ - and $\beta$-forms of 2-chlorobenzamide.

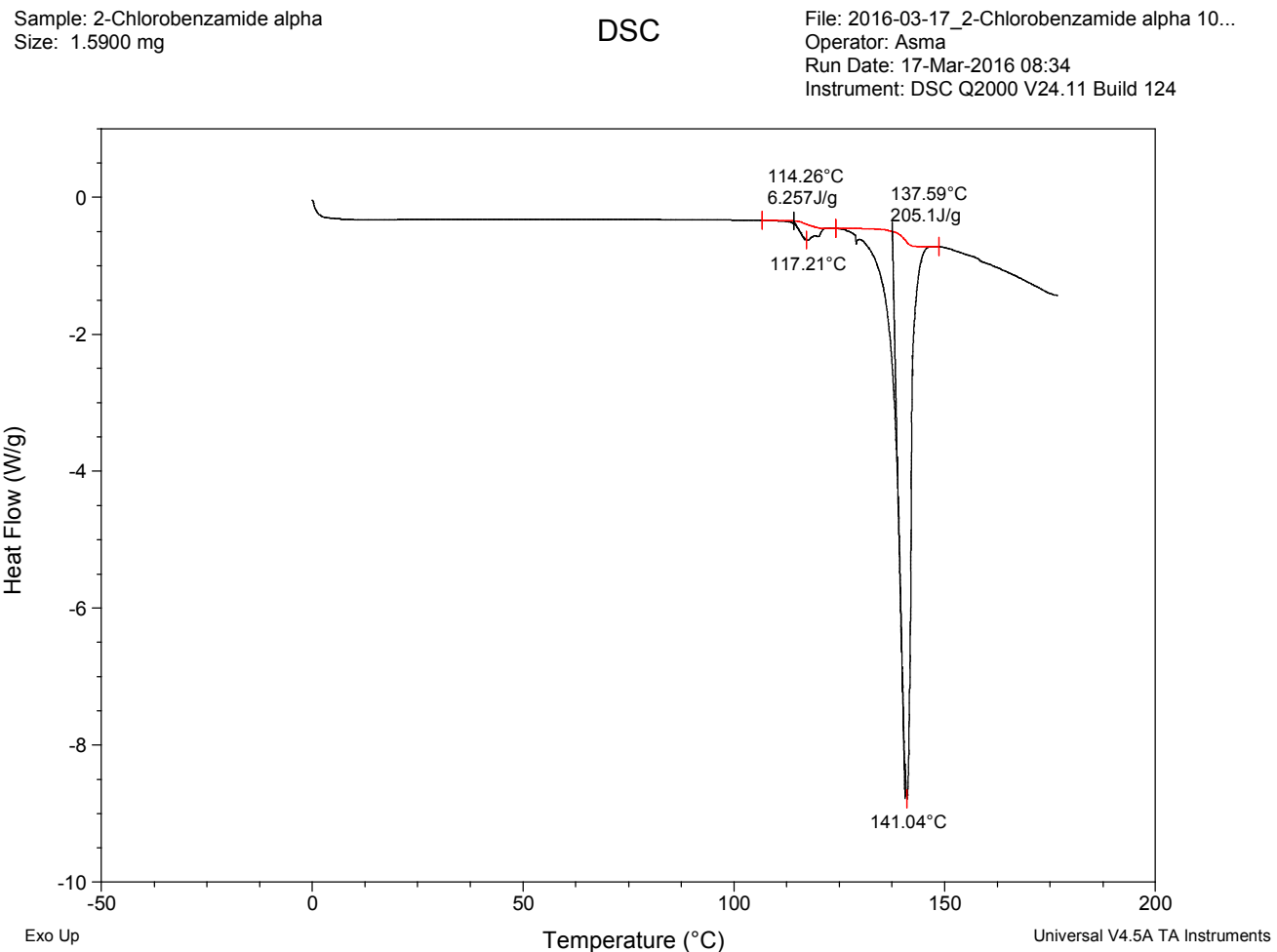

Figure SI 2.1. DSC thermogram of the $\alpha$-form (measured at $10{ }^{\circ} \mathrm{C} / \mathrm{min}$ ).

Sample: 2-Chlorobenzamide beta Size: $1.6300 \mathrm{mg}$

DSC

File: 2016-03-17_2-Chlorobenzamide beta 10C. Operator: Asma Run Date: 17-Mar-2016 09:52 Instrument: DSC Q2000 V24.11 Build 124

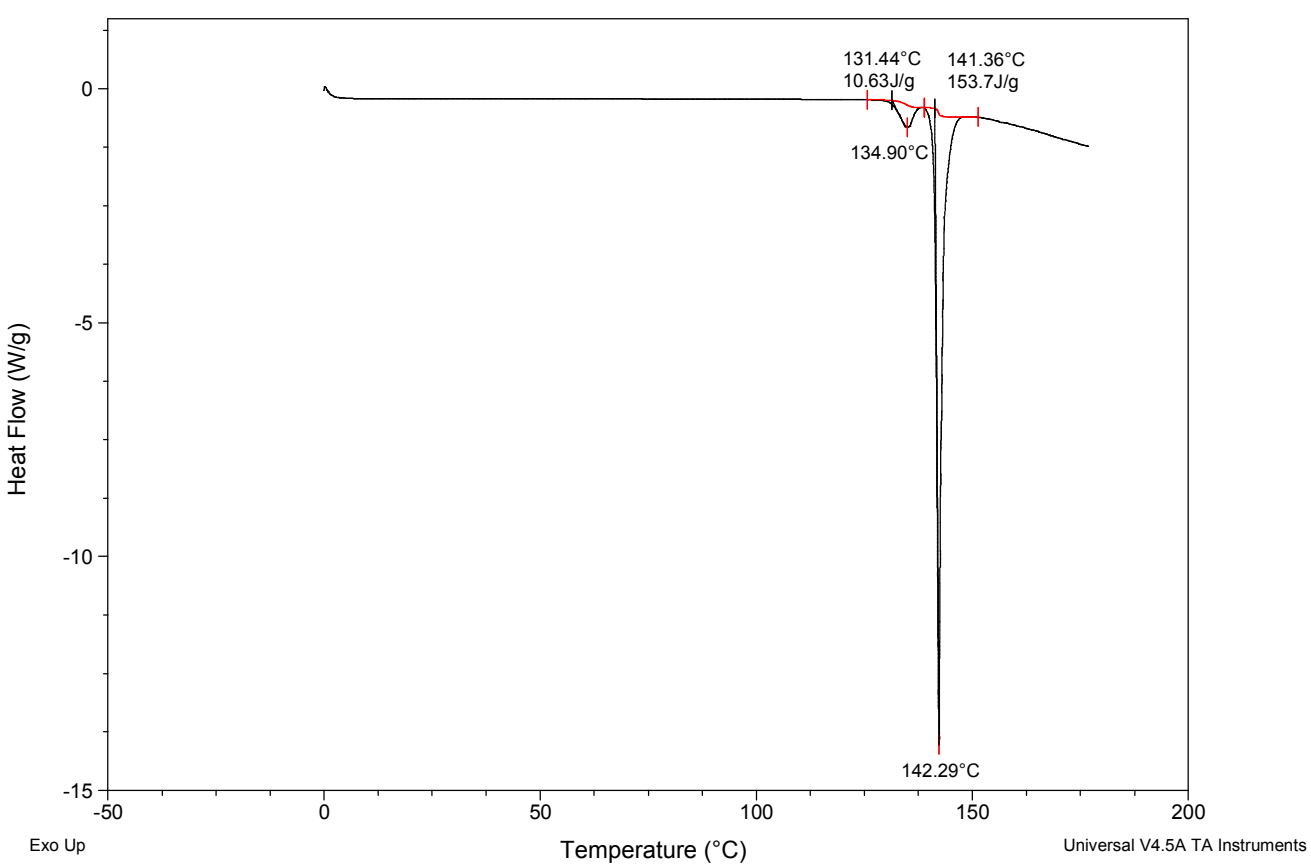

Figure SI 2.2. DSC thermogram of the $\beta$-form (measured at $10{ }^{\circ} \mathrm{C} / \mathrm{min}$ ). 


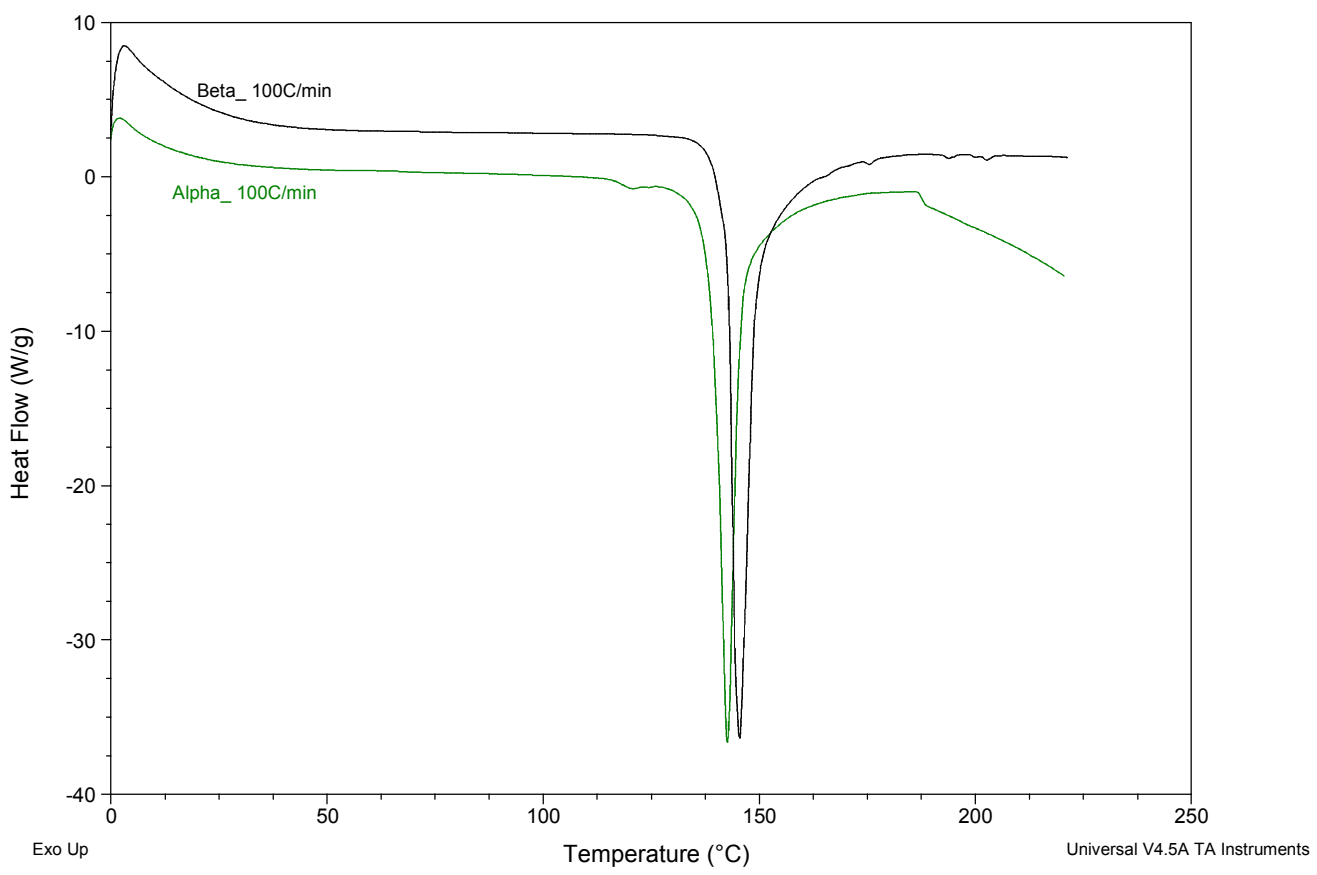

Figure SI 2.3. Comparative DSC thermograms of the $\alpha$ - and $\beta$-forms measured at $100^{\circ} \mathrm{C} / \mathrm{min}$.

N.B. Measurements were also obtained using a heating rate of $2{ }^{\circ} \mathrm{C} / \mathrm{min}$ but these offered no useful advantage. 


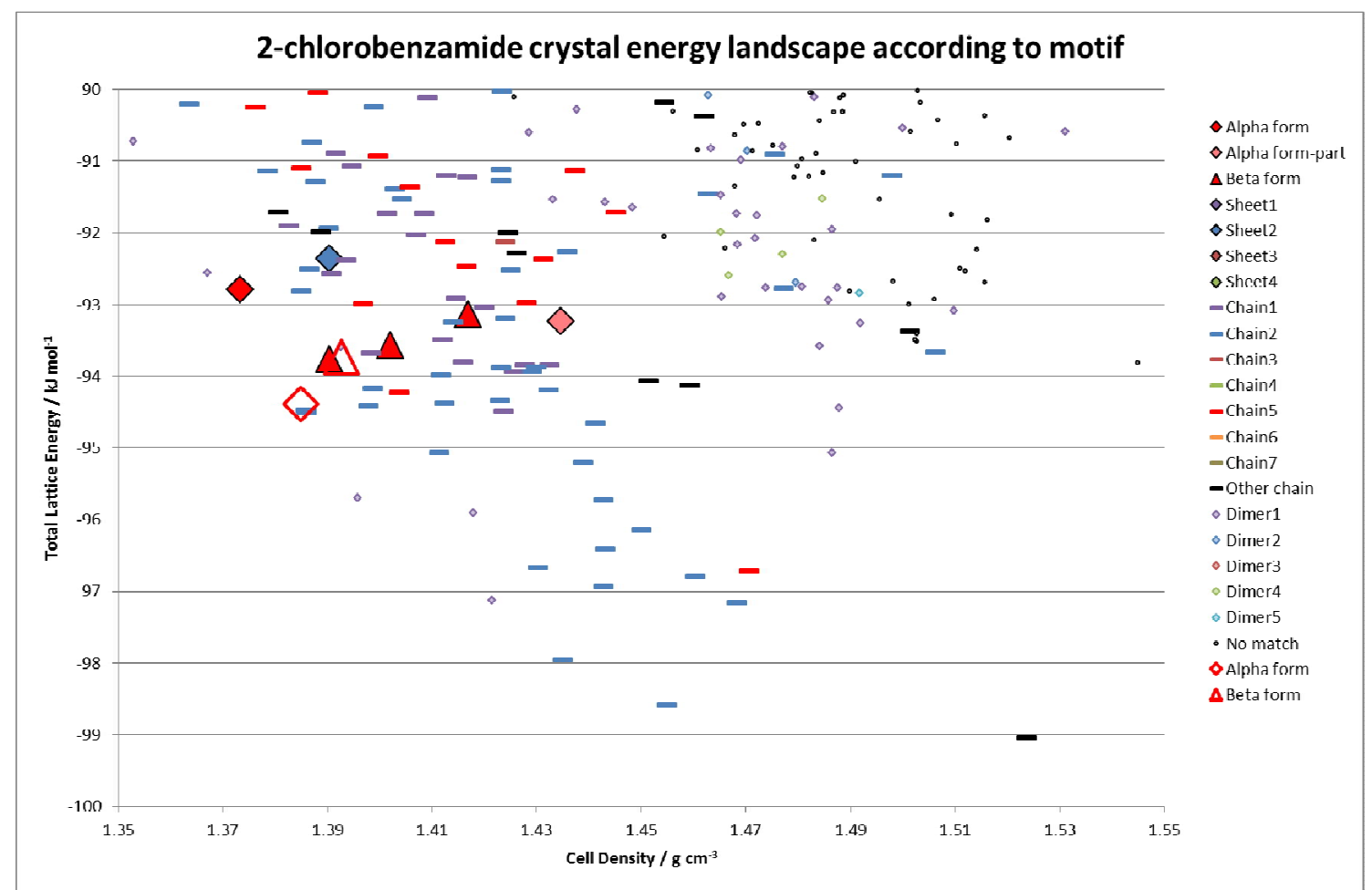

4. Figure SI 3. The crystal energy landscape of 2-chlorobenzamide according to motif matches with the experimental forms. 


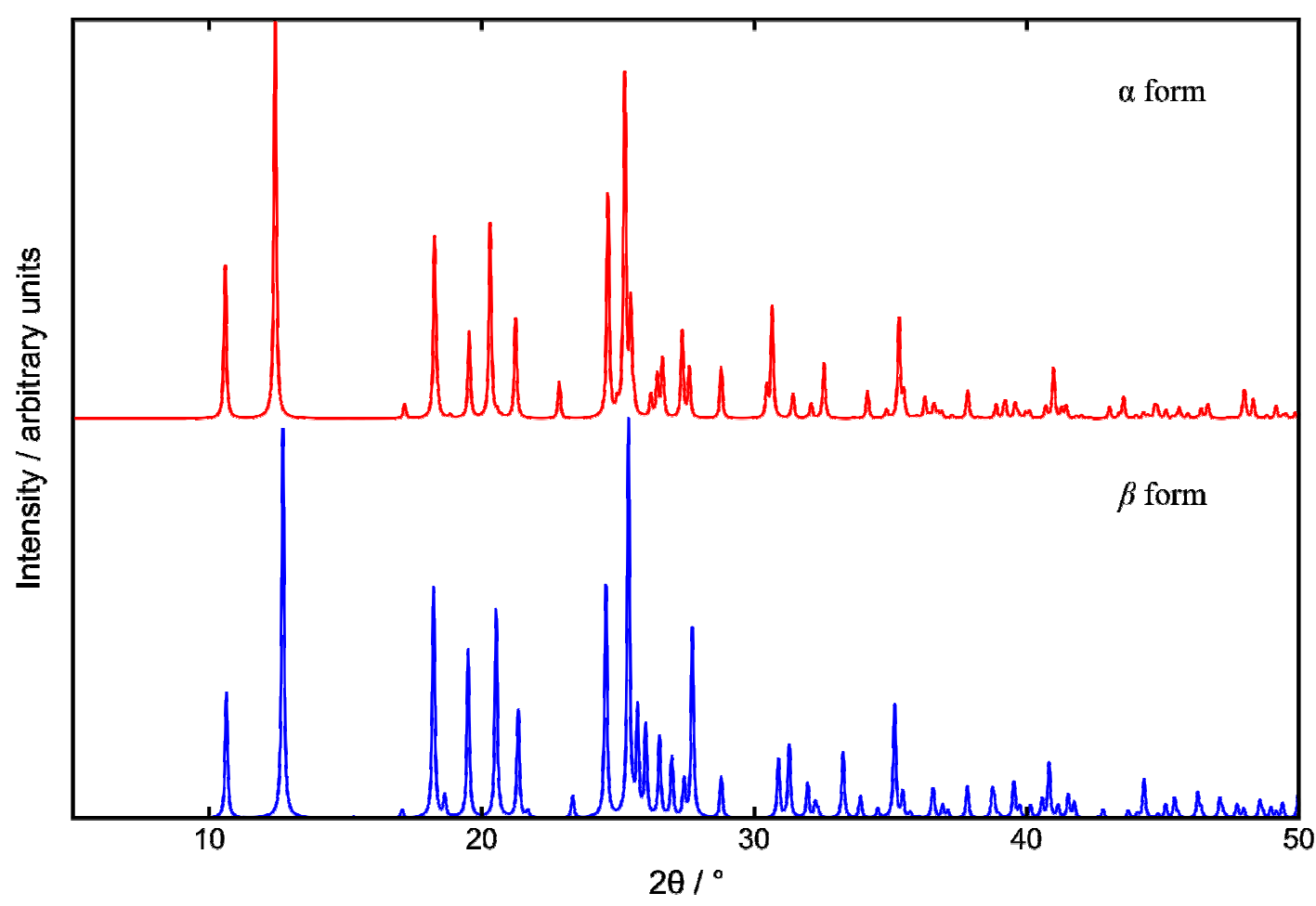

5. Figure SI 4. Calculated powder patterns using the program Mercury ${ }^{\circ}$ (ver. 3.7, Cambridge Crystallographic Data Centre, 2015) from the experimentally determined single-crystal X-ray structures of 2-chlorobenzamide at $150 \mathrm{~K}$.

The original paper by Kato, Takaki, and Sakurai $(1974)^{1}$ used non-standard origins for both $\alpha$ and $\beta$-forms. The $\alpha$-form is readily transformed to $P 2_{1} / c$ with a centrosymmetric origin by $(1 / 4,0,1 / 4)$ translation to the original coordinates. An additional translation of $(0,0,-1)$ moves the molecule outside the unit cell as per the CSD refcode CLBZAM10. In the paper, the molecule in the $\beta$-form can be moved outside the unit cell by a $(0,0,-1)$ translation relative to the original coordinates as per CSD refcode CLBZAM11. However, this transform still requires the use of a non-standard origin for $P 2_{1} 2_{1} 2_{1}$ with the origin lying on the $2_{1}(y)$-axis as per the original 1974 paper (and not as given in CSD refcode CLBZAM11). Transformation to the standard setting requires a $(0,0,1 / 4)$ translation of the original coordinates.

In this paper, the re-determined crystal structures, with the crystals at $150 \mathrm{~K}$ and hydrogen positions determined, makes use of standard space-group settings but with $a<b<c$ in contrast to the original paper (where $a>b>c$ ). The 1974 coordinates $(x, y, z)$ for the $\alpha$-form can be transformed to the same setting $\left(x^{\prime}, y^{\prime}, z^{\prime}\right)$ as used in this paper using:

and the equivalent transform for the $\beta$-form is:

$$
\left(\begin{array}{l}
x^{I} \\
y^{\prime} \\
z^{l}
\end{array}\right)=\left(\begin{array}{rrr}
0 & 0 & 1 \\
0 & 1 & 0 \\
-1 & 0 & 0
\end{array}\right)\left(\begin{array}{l}
x \\
y \\
z
\end{array}\right)+\left(\begin{array}{c}
1 / 4 \\
1 / 2 \\
5 / 4
\end{array}\right)
$$

$$
\left(\begin{array}{l}
x^{\prime} \\
y^{\prime} \\
z^{\prime}
\end{array}\right)=\left(\begin{array}{rrr}
0 & 0 & -1 \\
0 & 1 & 0 \\
-1 & 0 & 0
\end{array}\right)\left(\begin{array}{l}
x \\
y \\
z
\end{array}\right)+\left(\begin{array}{c}
1 \\
14 \\
34
\end{array}\right)
$$

1. Y Kato, Y Takaki, and K Sakurai, Acta Crystallogr., Sect B. 1974, 30, 2683-2687. 
6. Results of the PXRD experiments on 2-chlorobenzamide.

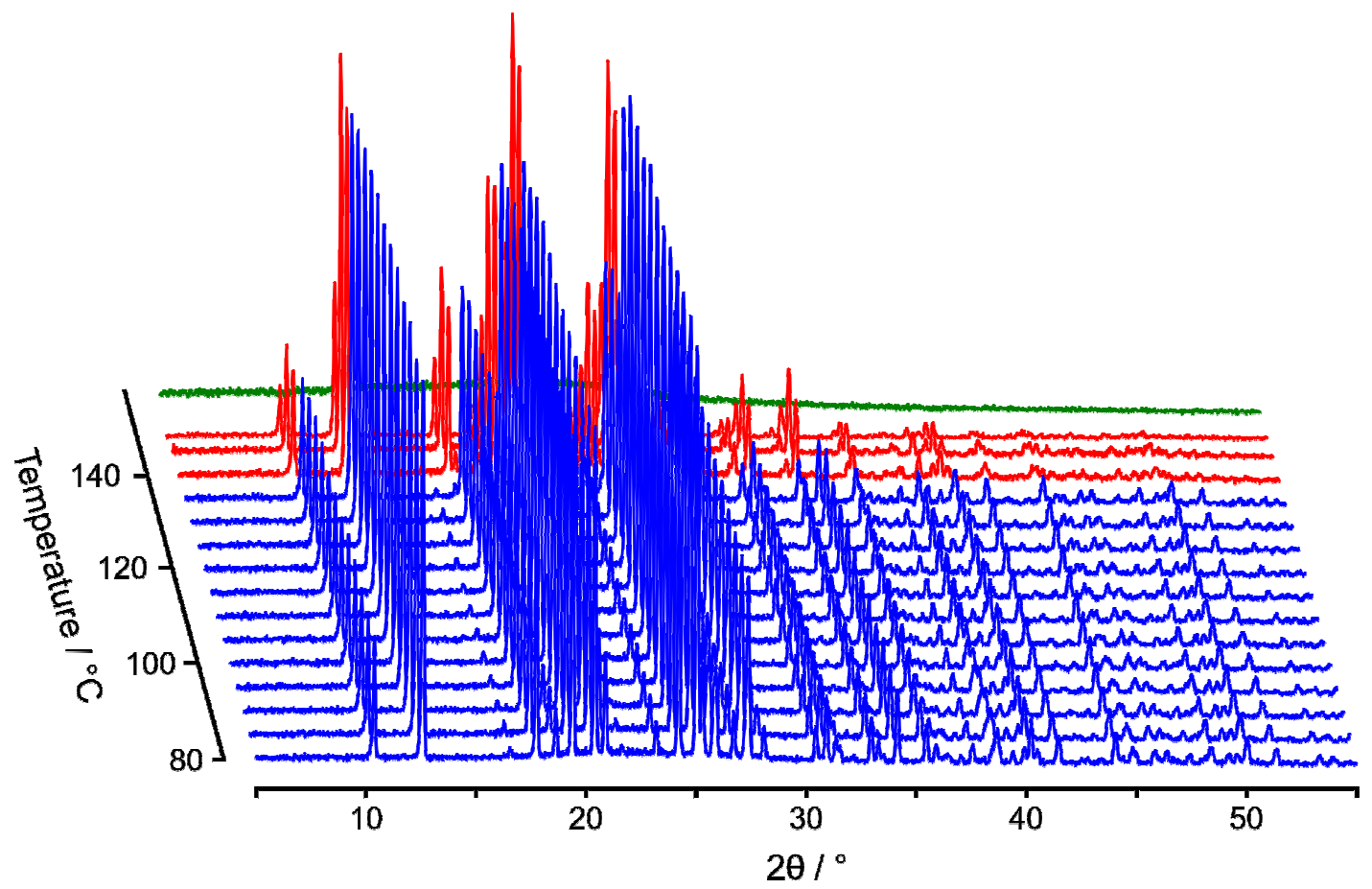

Figure SI 5.1. PXRD patterns of 2-chlorobenzamide supplied by Sigma Aldrich (Cat. No. $21606225 \mathrm{~g}$, Lot No. SHBB0035V) measured in a $0.7 \mathrm{~mm}$ borosilicate glass capillary on a Stoe STADI-P diffractometer equipped with a $\mathrm{Cu}$ X-ray tube $(\lambda=1.54056 \mathrm{~A})$, curved $\mathrm{Ge}$ (111) monochromator, a Dectris Mythen $1 \mathrm{~K}^{\circledR}$ detector, and an Oxford Instruments CryojetHT $^{\circledR}$ (range $90 \mathrm{~K}$ to $500 \mathrm{~K}$ ). Data were collected in $10 \mathrm{~K}$ intervals over the $2 \theta$ range 0 $60^{\circ}$ using a $0.5^{\circ}$ detector step, a count time of $5 \mathrm{~s} / \mathrm{step}$, and with the data binned in steps of $0.015^{\circ}$. Temperature control was enabled through the Oxcom software program developed inhouse (R. E. Ghosh, 2016). PXRD patterns shown in blue correspond to the $\beta$-form and those in red correspond to the $\alpha$-form; the pattern in green is of the molten sample at $155^{\circ} \mathrm{C}$. (The sample had already started to melt slowly at $150^{\circ} \mathrm{C}$ during the previous PXRD measurement). The experiment was repeated as a check on reproducibility. A similar experiment performed starting with the $\alpha$-form (Alfa Aesar, Cat. No. A15706 25g, Lot No. 10184293 25g) showed no phase transition (other than the melting point). 
Table SI 2.1. PXRD patterns of the $\alpha$-form 2-chlorobenzamide (as supplied by Alfa Aesar) were fitted over the $2 \theta$-range $5^{\circ}$ to $40^{\circ}$ by the method of Le Bail using the program Rietica (ver. 1.7.7, B. A. Hunter, 1997) to obtain the lattice parameters shown below.

\begin{tabular}{|c|c|c|c|c|c|}
\hline$T /{ }^{\circ} \mathrm{C}$ & $a / \AA$ & $b / \AA$ & $c / \AA$ & $\beta /{ }^{\circ}$ & $V / \AA^{3}$ \\
\hline-123 & $5.0571(1)$ & $10.3316(3)$ & $14.2489(5)$ & $91.921(3)$ & $744.06(4)$ \\
\hline-98 & $5.0538(2)$ & $10.3768(3)$ & $14.2199(5)$ & $91.544(4)$ & $745.44(4)$ \\
\hline-73 & $5.0532(2)$ & $10.4294(3)$ & $14.2113(5)$ & $91.240(4)$ & $748.79(4)$ \\
\hline-48 & $5.0513(1)$ & $10.4847(2)$ & $14.1911(5)$ & $90.979(3)$ & $751.48(4)$ \\
\hline-23 & $5.0502(1)$ & $10.5422(3)$ & $14.1759(4)$ & $90.712(3)$ & $754.67(3)$ \\
\hline 2 & $5.0487(1)$ & $10.6040(3)$ & $14.1552(5)$ & $90.517(3)$ & $757.79(3)$ \\
\hline 22 & $5.0567(2)$ & $10.6680(3)$ & $14.1560(5)$ & $90.284(4)$ & $763.63(4)$ \\
\hline 52 & $5.0476(1)$ & $10.7396(3)$ & $14.1162(4)$ & $90^{+}$ & $765.22(4)$ \\
\hline 80 & $5.0524(3)$ & $10.8383(6)$ & $14.0998(9)$ & $89.737(4)$ & $772.09(8)$ \\
\hline 90 & $5.0502(3)$ & $10.8689(5)$ & $14.0857(9)$ & $89.638(4)$ & $773.15(8)$ \\
\hline 100 & $5.0499(2)$ & $10.9057(3)$ & $14.0729(5)$ & $89.536(4)$ & $775.01(5)$ \\
\hline 110 & $5.0493(2)$ & $10.9412(3)$ & $14.0567(6)$ & $89.427(5)$ & $776.53(5)$ \\
\hline 120 & $5.0483(2)$ & $10.9805(3)$ & $14.0435(5)$ & $89.331(4)$ & $778.42(5)$ \\
\hline 130 & $5.0479(2)$ & $11.0236(3)$ & $14.0227(5)$ & $89.197(4)$ & $780.23(5)$ \\
\hline 140 & $5.0467(2)$ & $11.0654(4)$ & $14.0084(6)$ & $89.087(4)$ & $782.18(4)$ \\
\hline
\end{tabular}

${ }^{\dagger}$ The value of $\beta$ was fixed at $90^{\circ}$ in this refinement as it was indistinguishable from $90^{\circ}$. 
Table SI 2.2. PXRD patterns of the $\beta$-form 2-chlorobenzamide (as supplied by Sigma Aldrich) were fitted over the $2 \theta$-range $5^{\circ}$ to $40^{\circ}$ by the method of Le Bail using the program Rietica (ver. 1.7.7, B. A. Hunter, 1997) to obtain the lattice parameters shown below. This experiment was repeated several weeks later and the values of the lattice parameters reported below for equivalent temperatures are in acceptable agreement. Unfortunately no data was obtained on a sample at $150 \mathrm{~K}\left(-123^{\circ} \mathrm{C}\right)$ and so the values from the single-crystal measurement at $150 \mathrm{~K}$ were used as baseline values to monitor the changes in lattice parameters shown in the lower graph of Figure SI 5.2 (below).

\begin{tabular}{|c|c|c|c|c|c|c|c|c|}
\hline & \multicolumn{4}{|c|}{ First Experiment } & \multicolumn{4}{|c|}{ Repeat Experiment } \\
\hline$T /{ }^{\circ} \mathrm{C}$ & $a / \AA$ & $b / \AA$ & $c / \AA$ & $V / \AA^{3}$ & $a / \AA$ & $b / \AA$ & $c / \AA$ & $V / \AA^{3}$ \\
\hline-98 & $5.0580(1)$ & $10.4152(2)$ & $13.9455(4)$ & $734.64(3)$ & & & & \\
\hline-73 & $5.0580(1)$ & $10.4484(2)$ & $13.9587(3)$ & $737.69(2)$ & & & & \\
\hline-48 & $5.0583(1)$ & $10.4826(2)$ & 13.9729(3) & $740.91(2)$ & & & & \\
\hline-23 & $5.0584(1)$ & $10.5186(2)$ & 13.9880(3) & $744.27(2)$ & & & & \\
\hline 2 & $5.0590(1)$ & $10.5551(2)$ & $14.0005(3)$ & $747.60(2)$ & & & & \\
\hline 22 & $5.0574(1)$ & $10.5867(2)$ & $14.0148(4)$ & $750.36(3)$ & & & & \\
\hline 35 & & & & & $5.0601(1)$ & $10.6086(3)$ & $14.0256(4)$ & $752.90(3)$ \\
\hline 40 & $5.0579(1)$ & $10.6156(2)$ & $14.0258(3)$ & $753.08(3)$ & & & & \\
\hline 50 & $5.0580(1)$ & $10.6327(2)$ & $14.0308(3)$ & $754.59(3)$ & & & & \\
\hline 60 & $5.0580(1)$ & $10.6509(2)$ & $14.0360(4)$ & $756.15(3)$ & & & & \\
\hline 70 & $5.0589(1)$ & $10.6709(2)$ & $14.0430(4)$ & $758.09(3)$ & & & & \\
\hline 80 & $5.0589(1)$ & $10.6898(2)$ & $14.0487(4)$ & $759.73(3)$ & $5.0607(1)$ & $10.6866(2)$ & $14.0497(4)$ & $759.83(3)$ \\
\hline 85 & & & & & $5.0606(1)$ & $10.6973(2)$ & $14.0536(4)$ & $760.78(3)$ \\
\hline 90 & $5.0589(1)$ & $10.7093(1)$ & $14.0529(4)$ & $761.34(3)$ & $5.0606(1)$ & $10.7070(2)$ & 14.0559(4) & $761.60(3)$ \\
\hline 95 & & & & & $5.0605(1)$ & $10.7163(2)$ & $14.0589(4)$ & $762.41(3)$ \\
\hline 100 & $5.0585(1)$ & $10.7304(2)$ & $14.0591(4)$ & $763.12(3)$ & $5.0606(1)$ & $10.7262(2)$ & $14.0602(4)$ & $763.20(3)$ \\
\hline 105 & & & & & $5.0604(1)$ & $10.7365(2)$ & $14.0636(4)$ & $764.09(3)$ \\
\hline 110 & $5.0583(1)$ & $10.7523(2)$ & $14.0646(4)$ & $764.95(3)$ & $5.0603(1)$ & $10.7473(2)$ & $14.0661(4)$ & $764.98(3)$ \\
\hline 115 & $5.0581(1)$ & $10.7623(2)$ & $14.0661(4)$ & $765.72(3)$ & $5.0604(1)$ & $10.7573(2)$ & $14.0682(4)$ & $765.82(3)$ \\
\hline 120 & $5.0577(1)$ & $10.7744(2)$ & $14.0685(4)$ & $766.63(3)$ & $5.0604(1)$ & $10.7684(2)$ & $14.0702(5)$ & $766.71(3)$ \\
\hline 125 & $5.0578(1)$ & $10.7854(2)$ & $14.0709(4)$ & $767.57(3)$ & $5.0603(1)$ & $10.7793(2)$ & $14.0734(4)$ & $767.65(3)$ \\
\hline 130 & $5.0575(1)$ & $10.7977(2)$ & $14.0730(4)$ & $768.52(3)$ & $5.0604(1)$ & $10.7901(2)$ & $14.0751(4)$ & $768.53(3)$ \\
\hline 135 & & & & & $5.0603(1)$ & $10.8008(2)$ & $14.0759(5)$ & $769.33(4)$ \\
\hline
\end{tabular}



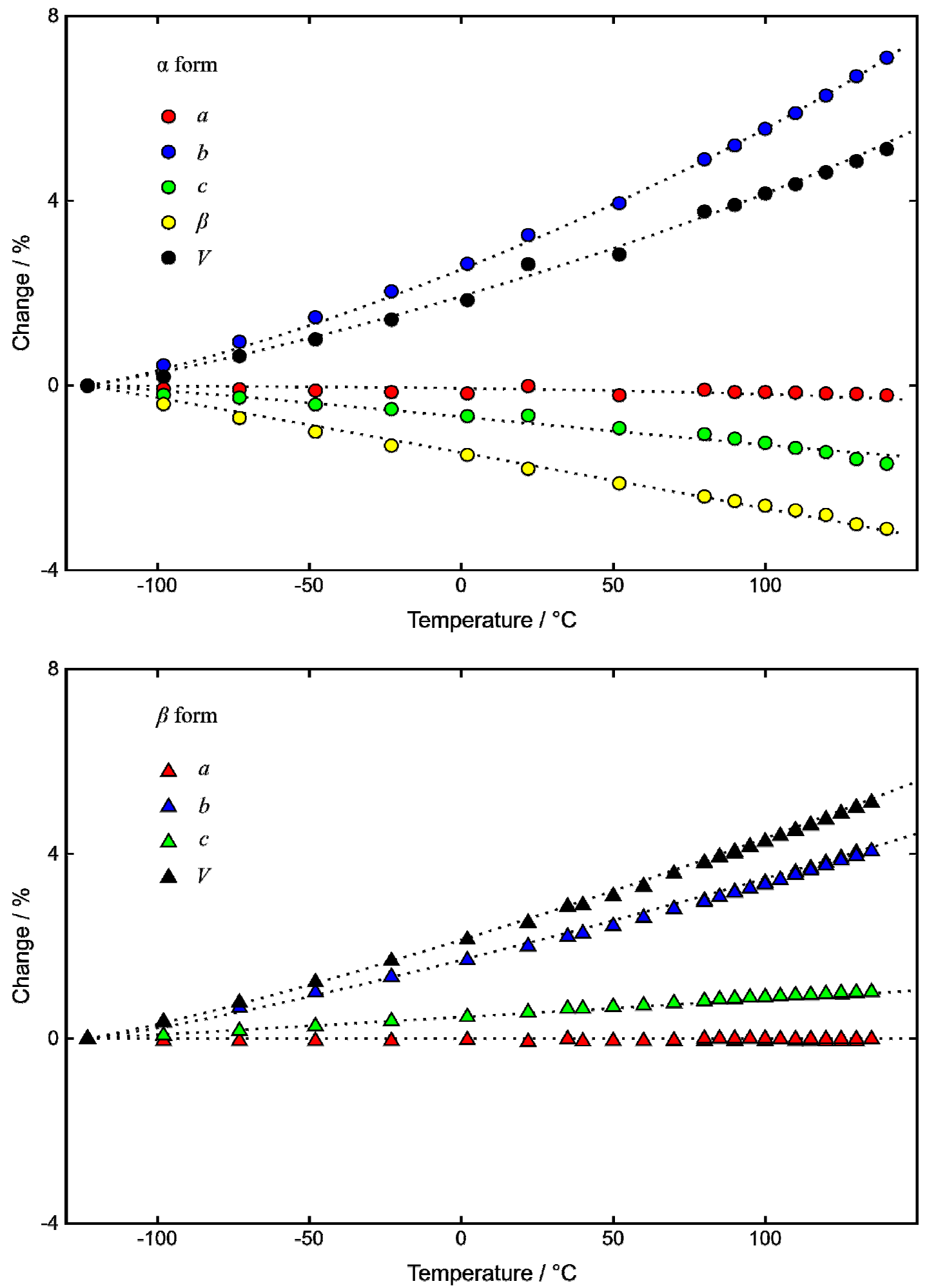

Figure SI 5.2. Graphs showing the relative change in lattice parameters and unit cell volume for (i) the $\alpha$-form (upper) and (ii) the $\beta$-form (lower) of 2 -chlorobenzamide as a function of temperature as determined by whole pattern fitting of the PXRD data relative to values obtained at $-123{ }^{\circ} \mathrm{C}$. Dotted lines are used as a guide to the eye only. 


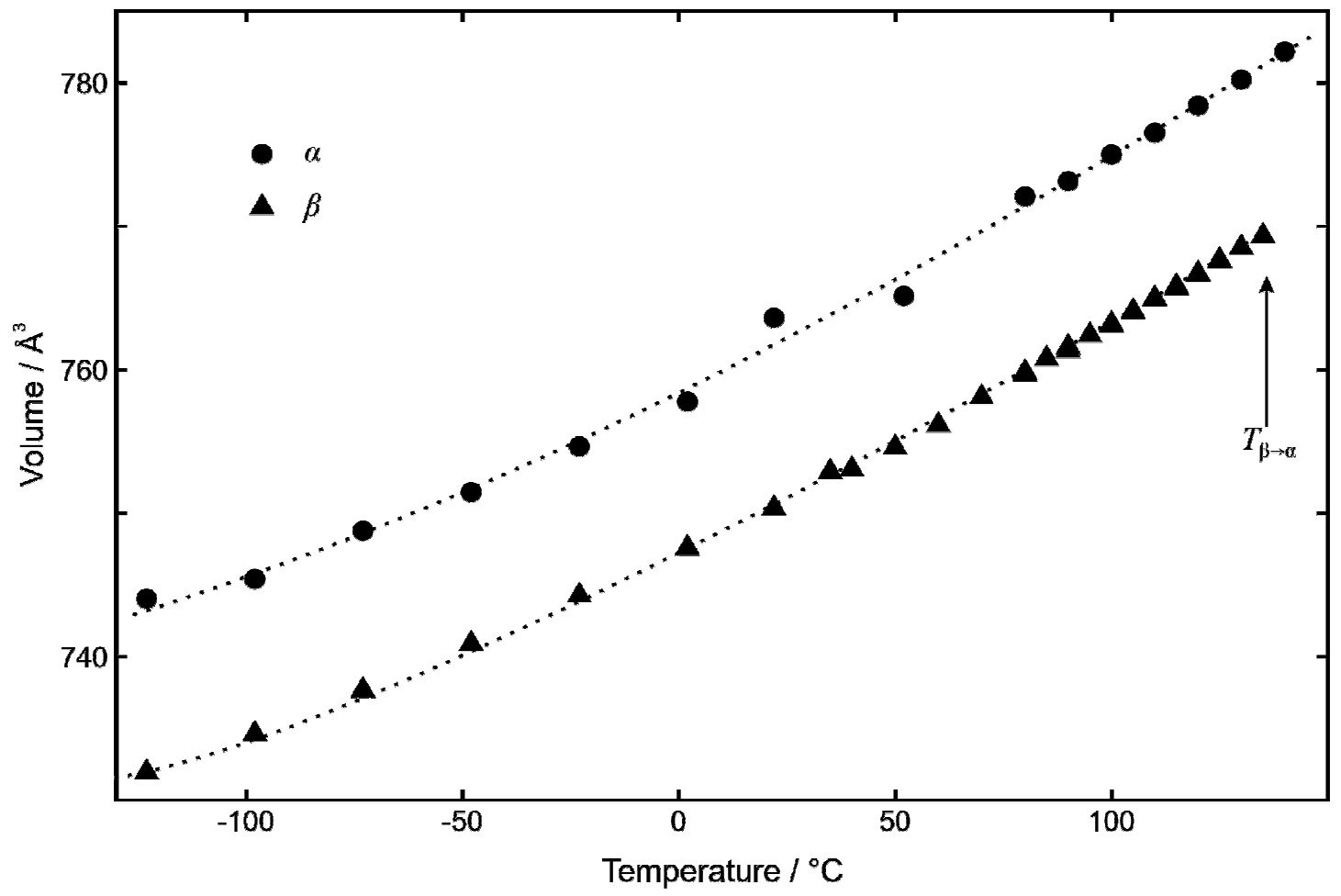

Figure SI 5.3. Graph showing the change in unit cell volume of the $\alpha$ - and $\beta$-forms of 2 chlorobenzamide as a function of temperature $(Z=4$ for both $\alpha$ - and $\beta$-forms). Dotted lines are used as a guide to the eye only. $T_{\beta \rightarrow \alpha}$ marks the temperature above which the beta form is no longer stable with respect to conversion to the $\alpha$-form. 


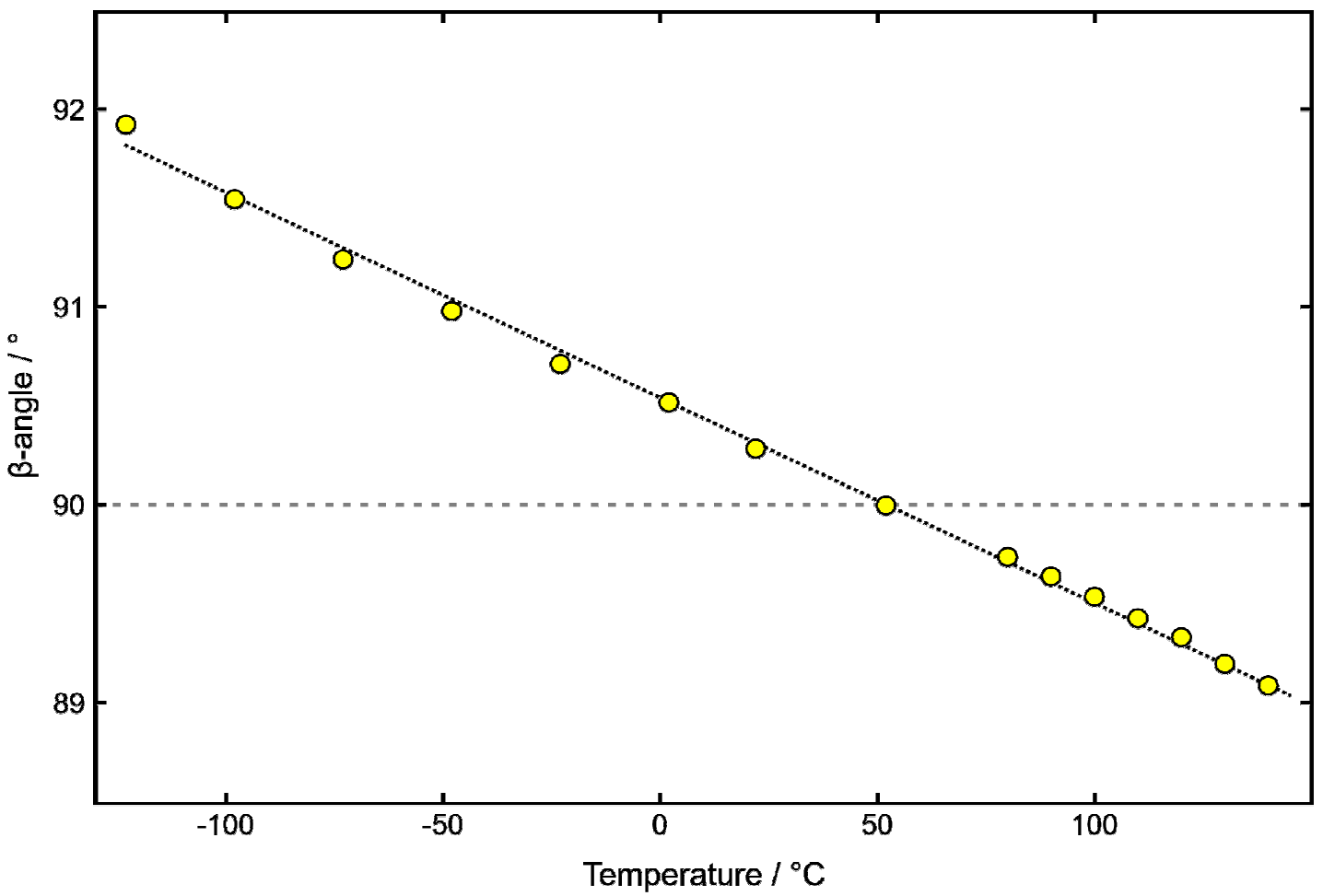

Figure SI 5.4. Graph showing the near linear variation in the monoclinic unit-cell angle $\beta$ for the $\alpha$-form of 2 -chlorobenzamide as a function of temperature. The value of $\beta$ crosses $90^{\circ}$ just above room temperature at about $50{ }^{\circ} \mathrm{C}$ and this explains the difficulty in identifying the form of 2-chlorobenzamide in a sample at RT using PXRD and $2 \theta$ peak positions alone. 